\title{
Interaction Designers' Use of Their Repertoire in Meetings with Clients
}

\author{
Per Sökjer \\ Human-Centered Systems \\ IDA, Linköpings universitet \\ 58183 Linköping, Sweden \\ +46 (0) 282609 \\ perso@ida.liu.se
}

\begin{abstract}
An important part of an interaction designer's work is meeting with clients during design sessions. It is of great importance that the designers participate in establishing some level of common ground. This research aims at investigating how designer's repertoire, in terms of facts, skills and examples, can help establishing common ground between designers and their clients. The research method is inspired by cognitive ethnography. Initial results from workshops, where interaction designers work together with participants from the Swedish Enforcement Authority, indicate that the interaction designers use examples from several design levels to establish common ground with clients and each other. Our future research aims to show how interaction designer and client work together in multidisciplinary teams.
\end{abstract}

\section{Categories and Subject Descriptors}

H.5.2 User Interfaces - User-Centered Design, K.6.1 Project and People Management - Systems analysis and Design

\section{General Terms}

Management, Documentation, Design, Human Factors, Theory

\section{Keywords}

Repertoire, objects, clients, procurement

\section{INTRODUCTION}

A designer participates in many communicative contexts. One critical and rather central situation is meetings with clients. We know that when a designer communicates with other designers the dialogue is facilitated by previous experience. This previous experience is sometimes called a repertoire and could be described as the facts, skills and examples available to the designer. A significant aspect of becoming a good interaction designer is building and maintaining this repertoire. This includes analyzing artifacts, using different tools for visualization depending on purpose and audience and getting experience working in projects [1]. Building and maintaining a repertoire should be part of every interaction designer's central competence since it's a cognitive resource for defining problem

(C) P. Sökjer, 2007

Published by the British Computer Society

Volume 2 Proceedings of the 21 st BCS HCI Group Conference HCI

2007, 3-7 September 2007, Lancaster University, UK

Devina Ramduny-Ellis \& Dorothy Rachovides

(Editors) spaces and working towards solutions [3].

Common ground is the shared understandings that participants in a joint activity build their communication on [2]. One way to think about designer's common ground is in terms of shared repertoire. When meeting clients during design sessions it is of great importance that the designers help the session participants establishing some level of common ground. We believe that the repertoire of the designers play an important role in this activity. The question is what that role is, and how to study it. In the study described here we will investigate how designer's repertoire can help establishing common ground between designers and their clients.

\section{RESEARCH ISSUES}

In my research I want to develop a theoretical and empirical understanding of how interaction designers use their repertoire depending on situation and purpose. Initially I have chosen to focus on how designers use repertoire for communication, and to establish common ground, with clients. More specifically, the initial research perspective is to study the conceptual and material objects created, maintained and proposed by the interaction designers during these designer-client meetings. Objects evolve and resonate in this setting providing clues regarding repertoire in use.

\section{CONTRIBUTION}

This research has significance for HCI since it focuses on how the quality of multidisciplinary teamwork in design can be improved. By providing empirical evidence how the repertoire of the interaction designer contributes to establishing common ground between designer and client we can assess how this aspect influences the outcome of these meetings.

\section{METHOD}

To accomplish this research, a method inspired by cognitive ethnography will be used [5]. This framework provides perspectives that help capturing the dynamic and distributed nature of the multidisciplinary activities being observed. Video, interviews and participant observation are techniques that will be utilized.

This research is a part of an ongoing project where multiple organizations and institutions are involved. The project's main focus is to develop a design-oriented IT procurement organization. Swedish authorities are required by the government to work in a "clear delineation between procuring and developing department structures" The Swedish Enforcement Authority is involved in the project regarding the development of their procurement organization [6][4]. 
One part of this project lets team members from the procurement organization meet and work together with interaction designers in a series of workshops. The aim of these workshops is to allow the different competences to work together as teams. In the workshops the interaction designers provide tools and methods for defining problems, work toward possible solutions and present methods how to capture problems, important use qualities etc.

Researchers captured team activities using pen and paper and video for off site analysis. Material and objects produced during the workshops (sketches, models, user profiles etc) were also saved for later analysis.

The recorded material will be analyzed using methods and tools for video analysis. Different object definitions will be utilized when trying to capture the dynamic use and evolution of objects.

\section{CURRENT STATUS}

The workshops were carried out successfully during the autumn 2006. Members from the Swedish Enforcement Agency worked together with representatives from Swedish interaction design consultancy firms. The specified task the groups worked on was based on detailed work processes. These work processes were developed as part of the Swedish Enforcement Agency's reorganization process.

Data were collected through observation, video recording and still imaging by researchers present at the workshops. The data are for the moment being organized and transcribed.

\section{PRELIMINARY RESULTS}

Initial results indicate that the participating interaction designer's use examples from multiple design levels proposed by Markensten (business, activity, interaction and technology) [7] to establish common ground during the workshop sessions. These design levels are used when trying to define system requirements.

Results also indicate that objects shift "status" during the workshops and convey different properties, meanings and purposes to the participants at different stages of the process; an explorative visualization of different tasks evolves into a user interface concept.

\section{ACKNOWLEDGMENTS}

This research was made possible through a grant from VINNOVA, the Swedish innovation agency, in the project Enabling technology through usability and organizational change with focus on the procurers terms (2001-05131). I would like to thank my advisor Stefan Holmlid, Ann Lantz, Mattias Arvola, Jakob Tholander and Henrik Artman. Additional thanks to the participants from the Swedish Enforcement Authority and from the participating design companies.

\section{REFERENCES}

[1] Schön, D.A. (1987). Educating the Reflective Practitioner: Toward a New Design for Teaching and Learning in the Professions. San Francisco, CA: Jossey-Bass.

[2] Clark, H.H. (1996). Using Language. Cambridge, England: Cambridge University Press.

[3] Löwgren, J. and Stolterman, E. (2004). Thoughtful Interaction Design. A Design Perspective on Information Technology. Cambridge, Mass.: MIT Press.

[4] Holmlid, S. and Lantz, A. (2006). Developing e-services in a government authority: Different views on design in procurement and system development. NordiCHI workshop on User involvement and representation in eGovernment projects. Oslo, October.

[5] Hollan, J.D., Hutchins, E.L. and Kirsh, D. (2000). Distributed Cognition: Toward a New Foundation for Human-Computer Interaction Research. In ACM Transactions on Computer-Human Interaction, Vol. 7, No. 2.

[6] Artman, H. and Andersson, F. (2006). Communicating the Future Business: A Procurement Organizations Understanding of their Role in Systems Development. In A. Følstad, H. Artman, J. Krogstie (eds.) User Involvement and representation in e-Government projects. NordiCHI, Oslo, Oct. 15, 2006

[7] Markensten, E. (2005). Mind the Gap: A Procurement Approach to Integrating User-Centered Design in Contract Development. Licentiate Thesis. Stockholm, Sweden: Royal Institute of Technology. 